\title{
Concentrated Solar Thermoelectric Power
}

\begin{tabular}{|c|c|}
\hline \multicolumn{2}{|c|}{$\begin{array}{l}\text { MASSACHUSETTS INSTITUTE } \\
\text { OF TECHNOLOGY }\end{array}$} \\
\hline PROGRAM: & SunShot CSP R\&D 2012 \\
\hline TOPIC: & Advanced Power Cycles \\
\hline LOCATION: & Cambridge, Massachusetts \\
\hline $\begin{array}{l}\text { AWARD } \\
\text { AMOUNT: }\end{array}$ & Up to $\$ 1$ million \\
\hline PROJECT TERM: & 2012-2015 \\
\hline
\end{tabular}

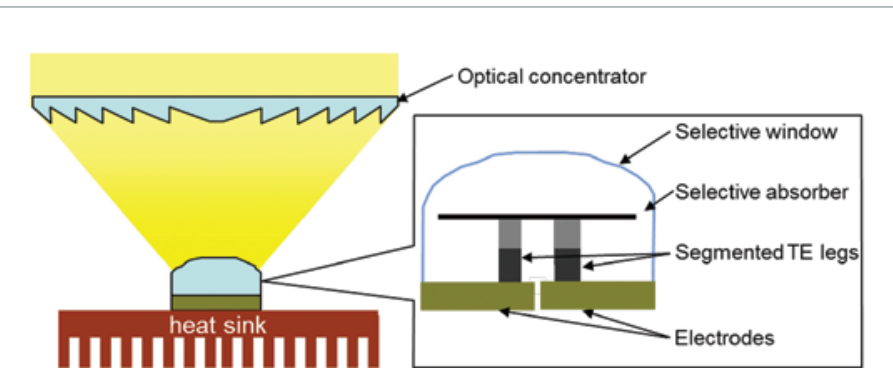

Thermoelectric energy conversion uses temperature difference across solids to convert heat into electricity. Concentrating solar thermoelectric generators (CSTEGs) have the potential to achieve greater than $10 \%$ solar-to-electrical energy conversion efficiency and provide electricity day and night. Illustration from MIT

\section{CONTACTS}

\section{Project Leader: $\quad$ Partnering Organization: \\ Dr. Gang Chen}

gchen2@mit.edu

\section{MOTIVATION}

Concentrating solar power (CSP) systems traditionally use mechanical power-generation blocks to convert solar heat into electricity. Representing about $15 \%$ of the total system cost, power blocks include the steam turbine, generator, and associated equipment such as condensers and water treatment systems. This project has the potential to replace traditional CSP power generation systems with concentrating solar thermoelectric generators (CSTEGs) that have greater than $10 \%$ solar-to-electrical energy conversion efficiency and 24-hour operation.

\section{PROJECT DESCRIPTION}

The research team previously demonstrated flat-panel solar thermoelectric generators (STEGs) that produce electricity by harnessing the sun's heat to create a $200^{\circ} \mathrm{C}$ temperature differential between the interior of the device and the surrounding air. These STEGs achieved a $4.6 \%$ solar-to-electric energy conversion efficiency with no optical concentration. The current effort is working to demonstrate CSTEGs with $>10 \%$ solar-to-electrical energy conversion efficiency while limiting optical concentration to less than a factor of 10 and potentially less than 4 .

\section{IMPACT}

Preliminary modeling carried out by the team shows that STEG system efficiencies of $10 \%-15 \%$ are achievable with small amounts of optical concentration. In addition, STEGs have shown great low-cost potential. When combined with thermal storage, CSTEGs have the potential to provide electricity day and night using no moving parts at both the utility and distributed scale.

For more information, visit the project page at: www.solar.energy.gov/sunshot/csp_sunshotrnd_mit.html. 